\title{
Estimation of the resource buffers in the assembly process of a shearer machine in the CPPM method
}

\author{
Aleksander Gwiazda ${ }^{1, *}$, Iwona Paprocka ${ }^{1}$, and Magdalena Bączkowicz ${ }^{1}$ \\ ${ }^{1}$ Silesian University of Technology, Faculty of Mechanical Engineering, Konarskiego 18A Str., 44- \\ 100 Gliwice, Poland
}

\begin{abstract}
Dynamic development of scheduling systems allows significantly improving currently realized tasks. Critical Chain Project Management (CCPM) is one of the methods of project management basing on network planning. In this method is utilized the concept of a critical chain derived from the Theory of Constraints. This method allows avoiding losses considered project time and resources. It results in quicker project implementation (20-30\%), and in reducing the risk level considered with tasks realization. The projects are cheaper, and the risk of cost overruns is significantly reduced. Factors that distinguish CCPM method from traditional network planning methods are: the balance of resources and the introduction of buffers. Moreover in the CCPM method key elements are: times of tasks that are reduced from traditional estimates to realistic ones. Activities associated with the task start as late as possible in accordance with the ALAP principle (As Late As Possible). This work presents the process of managing the assembly of a shearer machine taking into account the process of safety buffers utilization and the whole project optimization. It is presented the estimation of buffers capacity to obtain the improvement of project realization task.
\end{abstract}

\section{Introduction}

Critical Chain Project Management (CCPM) method is one of the network methods for planning, executing and managing projects in single and multi-project environments. It is distinguished from the other network methods. In particular, it differs in terms of: the scheduling procedure, the project constraints that are taken into account and the introduction of time stocks allowing avoid delays of tasks. Each project has some limitations, which are: costs, time and resources. So each project should be scheduled to achieve its objectives, taking into consideration these limitations. For this reason, it is important to appropriate manage the project already in its first phase, that means in the planning phase. Unfortunately, in many cases, the used project management system leads to the fact that the projects are not realized on time, with the ever increasing costs $[1,2]$. This is why new approaches to project management are under consideration.

* Corresponding author : aleksander.gwiazda@polsl.pl 
In order to avoid errors in the planning phase are being sought techniques that are appropriate to manage the project. Application of the proper project management methodology leads to increasing the likelihood of success and achieving significantly better results at a lower cost, less effort and in shorter time. The important factors that should be considered at the planning phase are: resources flexibility, unpredictability and uncertainty. CCPM is the method, which combines the most important features of good project management. It is a reliable technology for project management. One of the most important aspects of CCPM is the reasonable analysis of the project realization process. It is known that the time to complete a task is a statistically distributed. This means that the execution of the task may take a very short time, e.g. 3 days, or could last a very long time, e.g. 8 days. So time of a given task realization should be therefore appropriately chosen taking into account the factor of uncertainty in the given project management. The implementation of the tool such as the CCPM method allows shortening the project duration basing on the appropriate estimation of duration of all performed tasks. It is also possible to specify the spare time (safety buffers) [3 - 5].

\section{Safety buffers in the CCPM method}

CCPM is characterized by a different way of project scheduling. It is scheduled according to the ALAP (As Late As Possible) principle. In the other methods schedules are created according to the ASAP (As Soon As Possible) principle. In CCPM uncertainty and deviation from the schedule are natural factors affecting the duration of the project. The focus should be on managing the uncertainty and deviations that occur during the project and not to avoid them. The Critical Chain method application does not means the resignation from such activities as: project initiating, project objectives determining, determining the outputs of the project, determining the project stakeholders, defining project foredesign and limitations, determining the work division and finally the elaboration of the project diagram. The next stage is the elaboration of the schedule.

The schedule created according to the outlined guidelines will increase the likelihood that the project will be realized at the given time or even earlier [6]. It is elaborated in some previously defined steps [7]:

- elaboration of the net of dependences of planned tasks,

- estimation of aggressive times for particular project tasks,

- schedule elaboration,

- identification of the Critical Path,

- determining the Critical Chain (the Critical Path including the resources balancing),

- calculation of the size and placement of safety buffers,

- determining a new term of project realization.

A very important aspect of the project management resulting from the use of the CCPM method is its control. Safety buffers allow continuous monitoring of the entire project. This monitoring of safety buffers comes to continuous determining the level of their use. The main objective of the CCPM method is that the project buffer (main safety buffer) has not been used completely or has been used in full, but never more. If this objective is reached, it means that the project will be completed in the scheduled time (at the end of the project buffer or even earlier). In addition to control the project it is needed to determine the stage of its completion. For each project, the time values defining the progress of the project and the use of buffers are selected individually. They are dependent on the limitations and assumptions of the project. They should not be changed, however, during its lifetime. Buffer management ensures the effective risk management in the project $[8,9]$. 
According to Goldratt it could be distinguished three basic types of safety buffers [10]. This safety buffers are designated to protect the realistic project deadline: To these buffers include:

- project buffer: a unique and single buffer to protect the project deadline,

- feeding buffer: multiple buffers to protect parts of the critical chain,

- resource buffer: multiple artificial buffers that act as warning signals to assure the availability of resources.

The buffer management according to the CCPM method is determined as such utilization of the project buffer and feeding one to increase the safety time of the project baseline schedule. It guarantees, with a high probability, that the project will be timely completed. The size of buffers is determined according to the properties of the path or chain feeding by these buffers. It could be the length of the path, its total variance, its average resource use or the number of tasks it contains. In this paper is given an example of safety buffers utilization for the technical project management. This project relates to special, piece production system of a mining shearer loader. It is a coal cutting machine which is used in the hard coal industry (Figure 1).

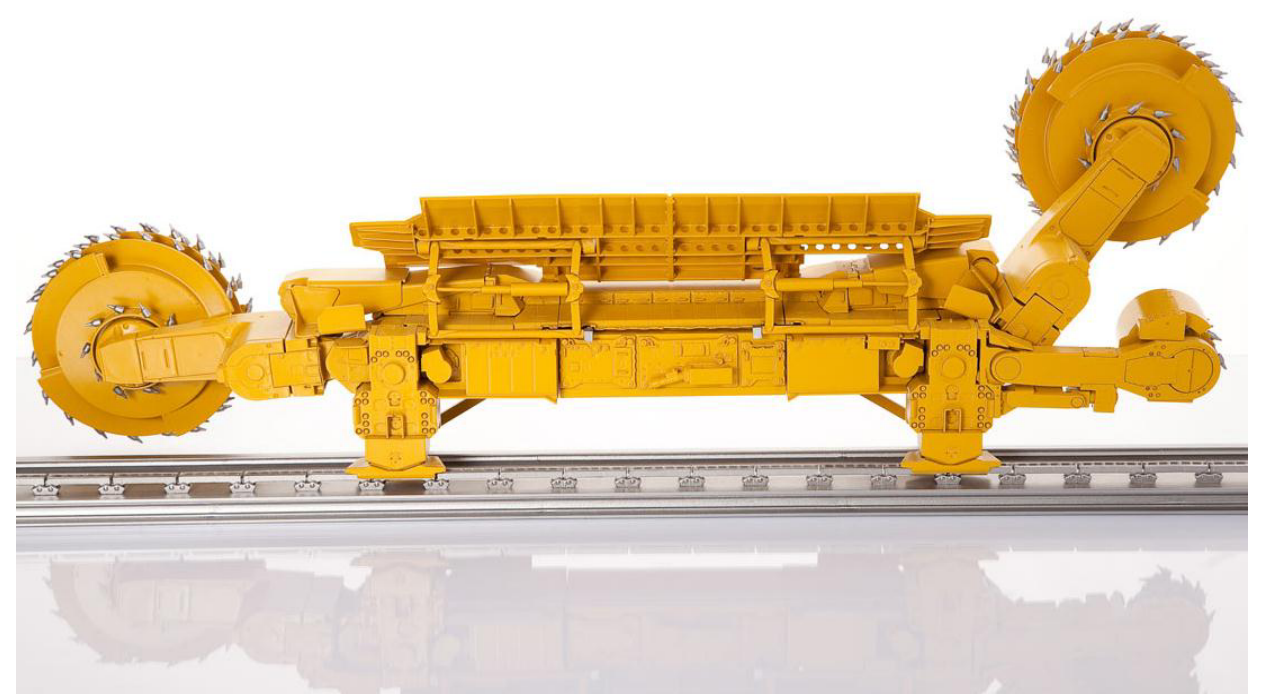

Fig. 1. Example of a mining shearer loader [11].

Shearer loader is a part of a mining complex $[12,13]$. Such complex is composed of three main components: a shearer loader, an armored conveyor (being the trace of the shearer - white color in the figure), and a line of mining powered roof supports (nonvisible in the figure). The cost of a mining complex prepared for specific mining conditions is equal to some millions euro. It decides that investigation for more flexible and less costs consuming method of productions and it organization is required.

The unique designing and producing system of each shearer loader, basic of course on a number of universal modules) was the main cause deciding in selecting the CCPM method.

\section{Shearer loader CCPM}

The network of dependences of the analyzed production project is presented in Table 1. It consists of 17 tasks that are ordered taking into account the resources conflict (lack of welders) that mainly influence the time of this project realization. 
Table 1. Network of dependences of realized tasks including the resources conflict.

\begin{tabular}{|c|c|c|c|c|c|c|}
\hline $\begin{array}{l}\text { Task } \\
\text { No }\end{array}$ & $\begin{array}{l}\text { Task } \\
\text { code }\end{array}$ & $\begin{array}{l}\text { Task } \\
\text { type }\end{array}$ & $\begin{array}{c}\text { Task name } \\
\text { (in parenthesis number of } \\
\text { subassemblies) }\end{array}$ & $\begin{array}{l}\text { Preceding } \\
\text { task No }\end{array}$ & $\begin{array}{c}\text { Task } \\
\text { duration } \\
\text { [days] }\end{array}$ & $\begin{array}{l}\text { Worker } \\
\text { symbol }\end{array}$ \\
\hline 1. & $\mathbf{A}$ & \multirow{9}{*}{ 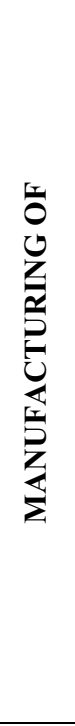 } & the ranging arm & $\mathrm{J}$ & 15 & $\mathrm{a}$ \\
\hline 2. & B & & the loader & - & 35 & $\mathrm{~b}$ \\
\hline 3. & $\mathbf{C}$ & & the cutting system & - & 35 & g \\
\hline 4. & D & & the cutting head & - & 20 & $\mathrm{~h}$ \\
\hline 5. & $\mathbf{E}$ & & $\begin{array}{l}\text { the transmission of the feed drive } \\
\text { (2) }\end{array}$ & $\mathrm{L}$ & 45 & $\mathrm{e}$ \\
\hline 6. & $\mathbf{F}$ & & the drive system & - & 45 & $\mathrm{c}$ \\
\hline 7. & G & & the electric drive (2) & $\mathrm{F}$ & 75 & $\mathrm{~b}$ \\
\hline 8. & H & & $\begin{array}{l}\text { the transforming-converting unit } \\
\text { BTP-1 }\end{array}$ & - & 70 & $\mathrm{f}$ \\
\hline 9. & I & & $\begin{array}{l}\text { the block of electric devices } \\
\text { BAE-18 (2) }\end{array}$ & - & 15 & $\mathrm{~g}$ \\
\hline 10. & $\mathbf{J}$ & \multirow{8}{*}{ 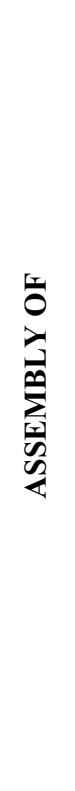 } & $\begin{array}{l}\text { the cutting head and the cutting } \\
\text { system }\end{array}$ & C, D & 30 & $\mathrm{a}$ \\
\hline 11. & $\mathbf{K}$ & & $\begin{array}{c}\text { the ranging arm with the loader } \\
\text { and subassembly obtained in the } \\
\text { task } \mathbf{1 0}\end{array}$ & A, B & 30 & $\mathrm{~h}$ \\
\hline 12. & $\mathbf{L}$ & & $\begin{array}{l}\text { the drive system with the electric } \\
\text { drive (2) }\end{array}$ & $\mathrm{F}, \mathrm{G}$ & 20 & $\mathrm{e}$ \\
\hline 13. & $\mathbf{L}$ & & $\begin{array}{l}\text { the transmission of the feed drive } \\
\text { and the subassembly obtained in } \\
\text { the task } \mathbf{1 2}\end{array}$ & $\mathrm{E}$ & 35 & d \\
\hline 14. & M & & $\begin{array}{l}\text { the subassembly obtained in the } \\
\text { task } \mathbf{1 3} \text { and the transforming- } \\
\text { converting unit BTP-1 }\end{array}$ & $Ł, H$ & 25 & $c$ \\
\hline 15. & $\mathbf{N}$ & & $\begin{array}{l}\text { the subassembly obtained in the } \\
\text { task } \mathbf{1 3} \text { and the block of electric } \\
\text { devices BAE-18 }\end{array}$ & M, I & 15 & $\mathrm{c}$ \\
\hline 16. & $\mathbf{O}$ & & $14+15$ & $\mathrm{~N}$ & 15 & d \\
\hline 17. & $\mathbf{P}$ & & $11+16$ & $\mathrm{~K}, \mathrm{O}$ & 10 & $\mathrm{e}$ \\
\hline
\end{tabular}

The network of dependencies between particular tasks was used to determine the critical path of the realized project. On the basis of the determined critical path and resources conflicts between some tasks it was determined the critical chain. The resources being in conflict are critical for this project because they are common (more precisely welders that work in the conflicted tasks). Using the elaborated schedule including the relationships 
between the tasks themselves and between tasks and feeding them resources as well as taking into account their duration it was also determined the duration of the entire project, which is 230 days.

Figure 2 shows the introduction of three resource buffers (BZi) that has been estimated on the basis of historical data using statistical analysis. They are marked in orange. In this figure tasks that are non-critical are market in blue and the ones that are critical are marked in red. According to this scheme the balanced resources are marked in green. The resource buffers were introduced in places where resources conflicts were previously detected. These buffers are located between the following tasks: L - E, M - N, J - A. The unit on the diagram below is equal to 1 week.

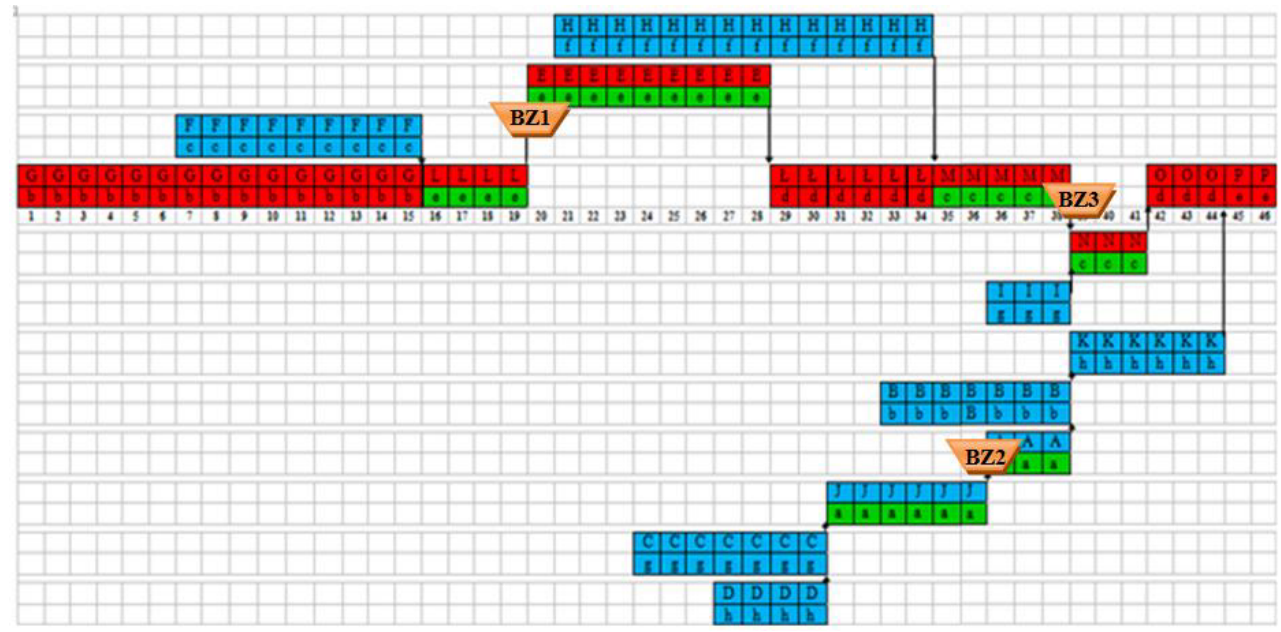

Fig. 2. Critical chain with resources buffers.

To determine the size of resource buffers (welders' availability) it was used the statistical analysis of historical data. These data concern the maximum use of resources which employees are assigned respectively to the task. In Table 2 are collected historical data on the time availability of the employee/welder "e" for the seven previously realized planning periods in the analyzed company. This table also shows the number of observations $\mathrm{L}_{\mathrm{i}}$ and $\mathrm{B}_{1}, \ldots \mathrm{B}_{\mathrm{Li}}$, which means employee uptime during the planning period. As the unit of time are taken days. For the planning period, in the analyzed company, it was taken last 3 quarters.

Table 2. Availability of the welder "e" $\left(\mathrm{B}_{1} \ldots \mathrm{B}_{\mathrm{Li}}\right)$ in seven preceding projects.

\begin{tabular}{|c|c|c|c|c|c|c|c|c|c|c|c|}
\hline $\mathbf{i}$ & $\mathbf{L}_{\mathbf{i}}$ & $\mathbf{B}_{\mathbf{1}}$ & $\mathbf{B}_{\mathbf{2}}$ & $\mathbf{B}_{\mathbf{3}}$ & $\mathbf{B}_{\mathbf{4}}$ & $\mathbf{B}_{\mathbf{5}}$ & $\mathbf{B}_{\mathbf{6}}$ & $\mathbf{B}_{\mathbf{7}}$ & $\mathbf{B}_{\mathbf{8}}$ & $\mathbf{B}_{\mathbf{9}}$ & $\mathbf{B}_{\mathbf{1 0}}$ \\
\hline 1 & 10 & 43 & 40 & 41 & 41 & 39 & 36 & 31 & 45 & 30 & 39 \\
\hline 2 & 10 & 32 & 42 & 37 & 35 & 27 & 21 & 40 & 32 & 36 & 20 \\
\hline 3 & 10 & 38 & 43 & 36 & 21 & 38 & 26 & 20 & 25 & 38 & 40 \\
\hline 4 & 10 & 37 & 41 & 35 & 28 & 22 & 44 & 37 & 33 & 19 & 37 \\
\hline 5 & 10 & 28 & 41 & 40 & 42 & 39 & 34 & 24 & 45 & 38 & 43 \\
\hline 6 & 10 & 30 & 42 & 43 & 23 & 42 & 41 & 22 & 25 & 29 & 27 \\
\hline 7 & 10 & 35 & 40 & 25 & 44 & 27 & 23 & 26 & 29 & 25 & 28 \\
\hline
\end{tabular}

To conduct the statistical analysis of the welder "e" availability it was used the program Statistica. It was realized the analysis of data matching to particular, basic statistical distributions using the Kolmogorov-Smirnov test. It proved the correlation with the normal distribution. Next there was elaborated histogram of analyzed data (ordering each of $\mathrm{B}_{\mathrm{i}}$ 
columns). Exemplar histograms, obtained in the Statistica program, are presented in Figure 3.
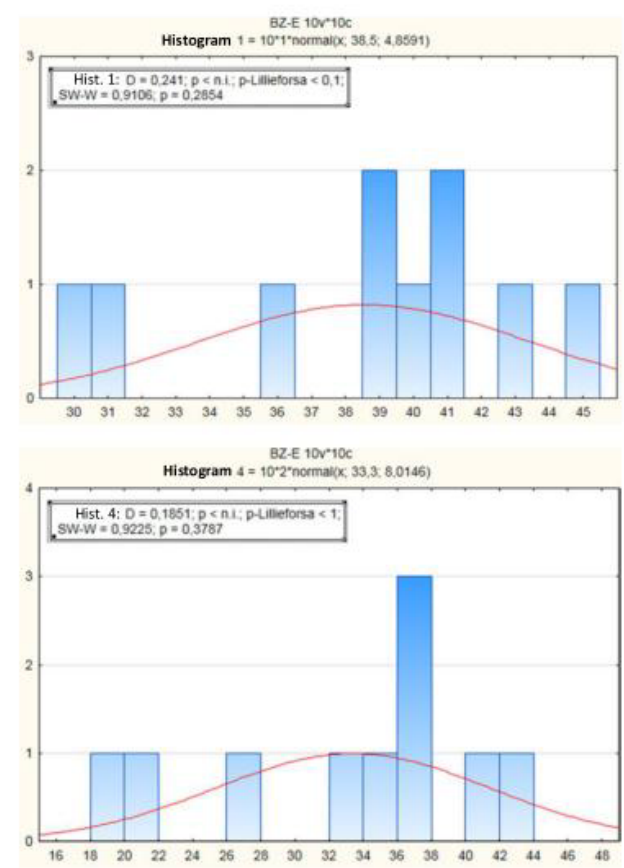

Fig. 3. Exemplar histograms chosen for analyzed variables.

The realized analysis allow elaborating, using the Statistica program, the prognosis of the welder "e" availability in the next prognosis period, taking into account the normal distribution of analyzed data. After analysis of trends and distribution parameters one obtained results presented in Table 3.

Table 3. Forecasted value for the next planning period.

\begin{tabular}{|c|c|}
\hline Curve equation & Results \\
\hline$\mu=0,018 \mathrm{x}^{2}-0,855 \mathrm{x}+37,02$ & $\mathbf{3 1 , 3 2 3}$ \\
\hline$\sigma=-0,209 \mathrm{x}^{2}+1,907 \mathrm{x}+3,98$ & 5,86 \\
\hline
\end{tabular}

This means that the resource " $\mathrm{e}$ " (welder) will be available to perform the tasks $\mathrm{L}$ and $\mathrm{E}$ on average for 32 days. To finally determine this resource buffer it must be also considered the downtime of the employee "e". This analysis was conducted analogously basic on the historical observation the previous planning periods. The result shows that the resource "e", in the next planning period will not be available to perform the tasks $\mathrm{L}$ and $\mathrm{E}$ on average for 10 days.

Estimation of this resource buffer was based on the historical data gathered during previous seven planning periods. The forecast showed that in the next planning period the availability of the analyzed resource, which the employee marked with an "e", will be 32 days. On the other hand, his unavailability is 10 days. Hence it could be concluded that 10 days is the time that is needed as a spare time to perform the tasks L and E. Assuming that the welder "e" will be available on the first day of this task realization, and the time of availability of the resource "e" is equal to the time of project tasks realization, one could estimate the size of this resource buffer. Therefore the duration of task L being realized by the resource "e" is 10 days. This means that the remaining time which may have the 
employee " $\mathrm{e}$ " is 22 days ( $32-10=22$ days). It is the time that could be attributed to the task E, which also is realized by the employee "e". In summary, the duration of the task L is estimated to be 10 days. After this task the BZ1buffer was introduced, sized to 10 days. Next 22 days is the estimated time to perform the task E. The location of the BZ1 buffer (in violet) is shown in Figure 4. It was elaborated in the Gantt Project program.

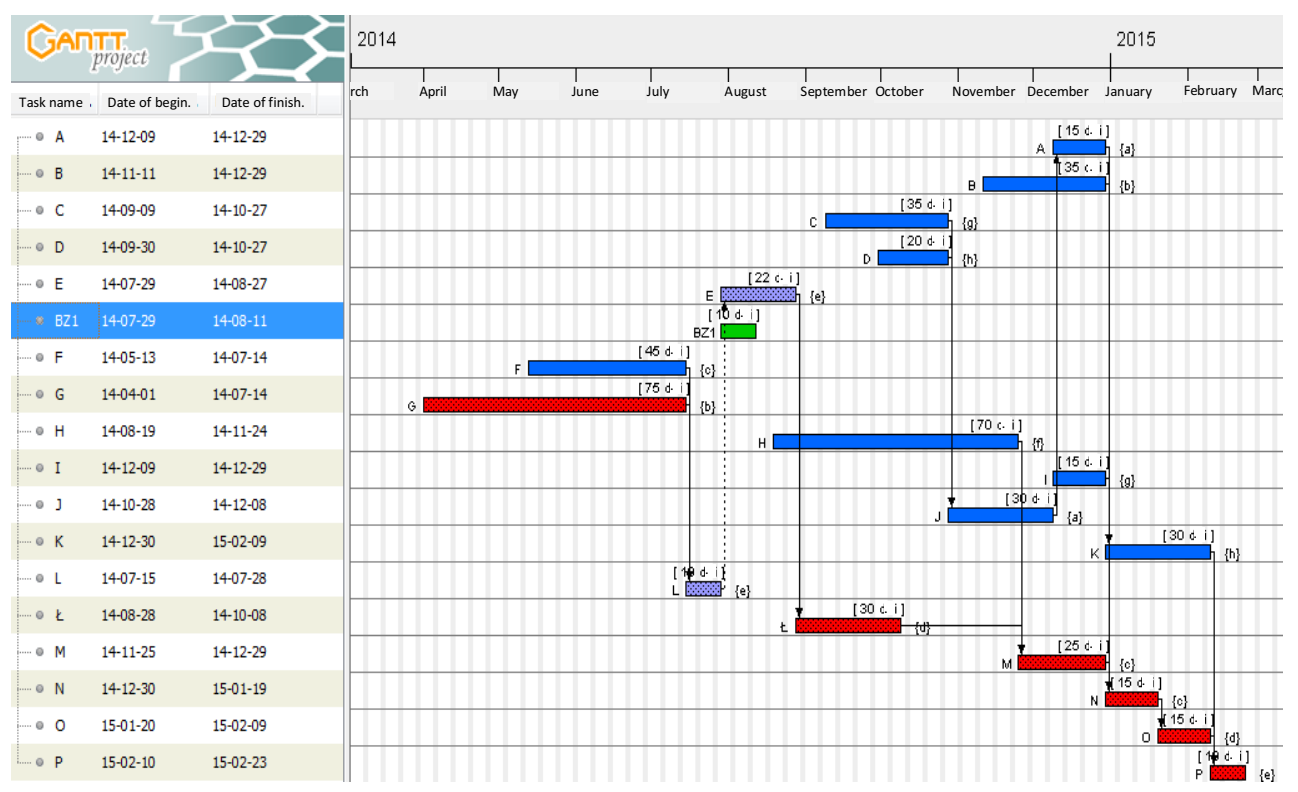

Fig. 4. Location of the BZ1 buffer (d. - days).

The other resource buffers (BZ2 and BZ3) were determined analogously. The next type of safety buffers that was introduced in this project was the feeding buffer BZA (Figure 5).

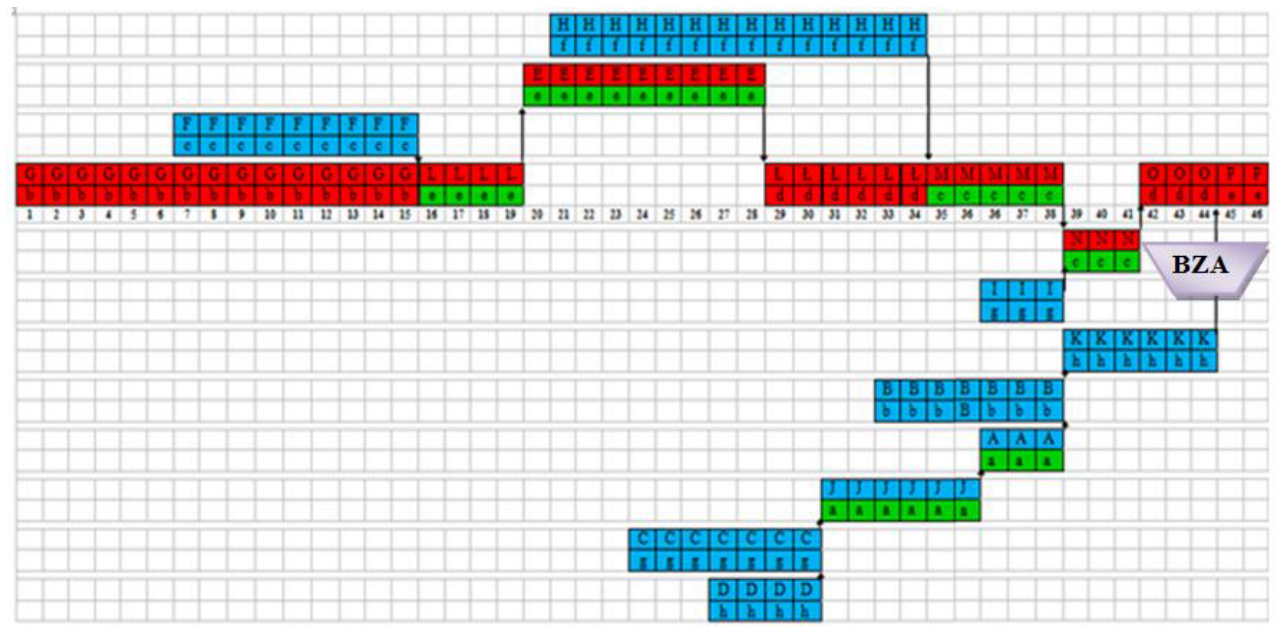

Fig. 5. Location of the BZA buffer.

The main task of the feeding buffer is to protect the critical chain. For the analyzed case it was determined the location of the feeding buffer BZA at the end of non-critical tasks. Its size was determined basing on safe and aggressive estimates. The protected is the next string of project tasks: K - B - A - J - C - D. After statistical analysis it was elaborated the 
Gannt diagram including the BZA buffer (9 days). It is presented in green in the diagram below (Figure 6).

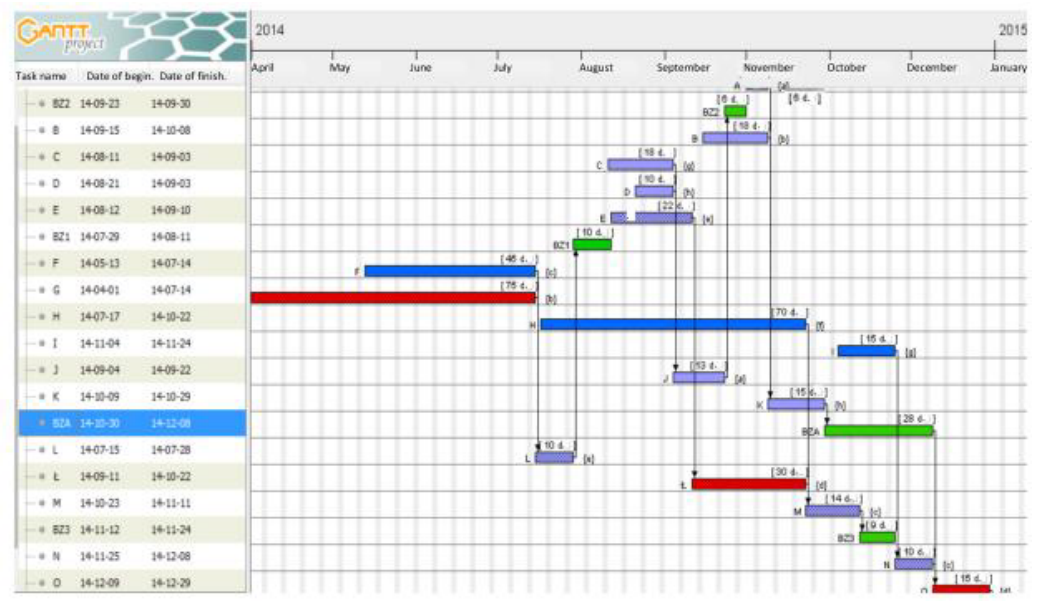

Fig. 6. Gantt diagram with the BZA buffer (d. - days).

The conducted works according estimating the duration of analyzed tasks and entering the BZA buffer allowed shortening the duration of the analyzed, non-critical tasks: K - B - A $\mathrm{J}-\mathrm{C}$ - D. Duration of the tasks K, B, C and D was shortened by 51 days. The size of the BZA buffer is 11 days. Finally it was introduced the project buffer BP, what is presented in Figure 7.

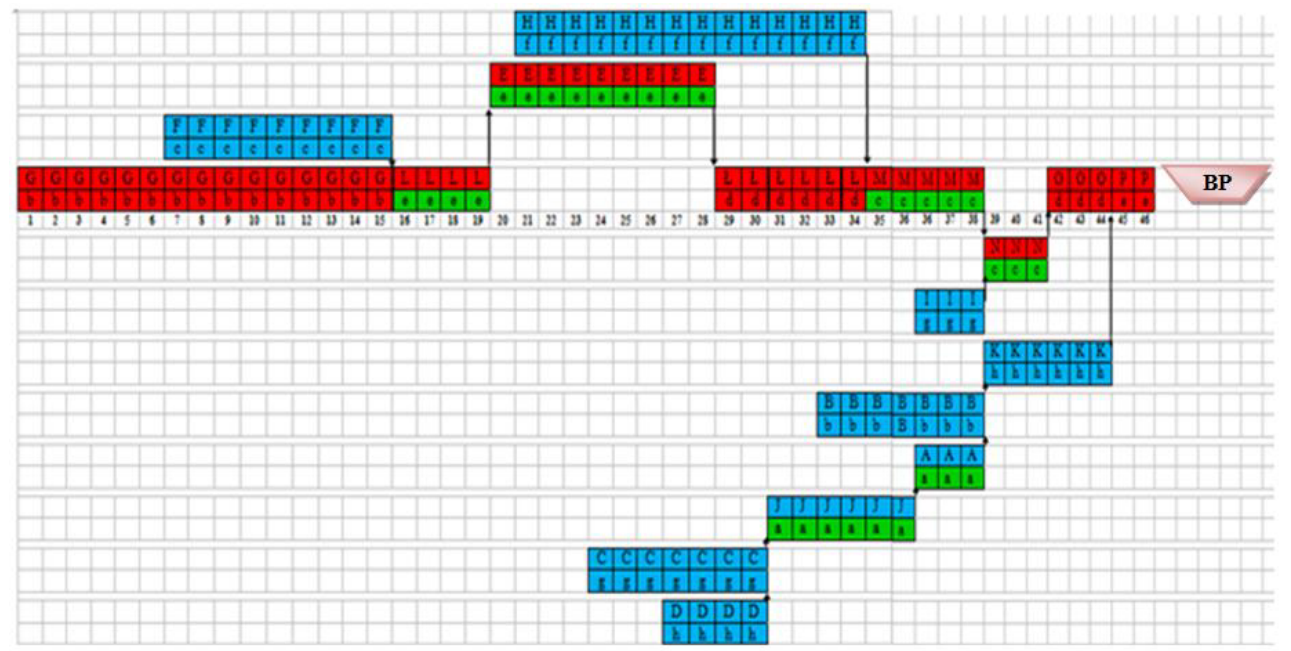

Fig. 7. Location of the PB buffer.

The project buffer is designed to protect the entire project against any delays that could occur during critical tasks realization. The buffer size was evaluated by two methods selected to compare the results. The first method is the half of the chain. The second method, used to calculate the buffer size of the project, was the Root Squared Error method. It was determined that the size of the project buffer PB should be equal to 29 days. The Gantt diagram, including all buffers analyzed in the project, is presented in Figure 8. The BZAi buffers represent feeding buffers designated for individual tasks. 


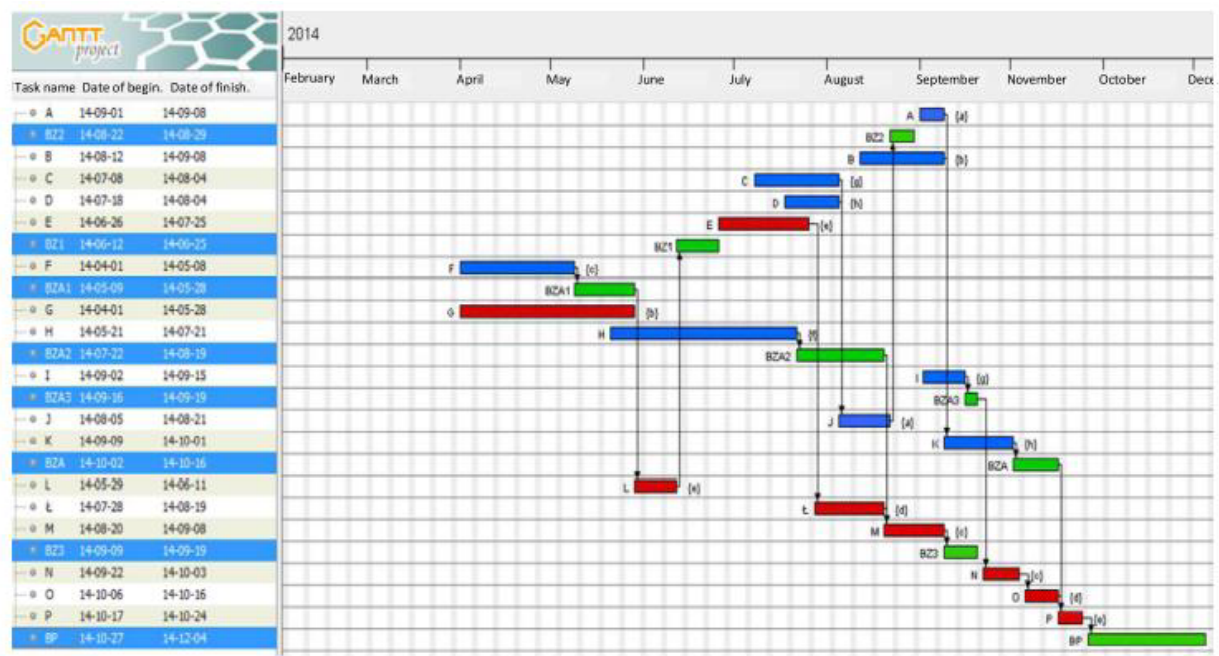

Fig. 8. Gantt diagram with the PB buffer.

The introduced changes resulted in the fact that the project completion date has to be changed. The changings are discussed in conclusion. It must be stated that the size of the BR buffer, estimated by the method of the half of the chain was 29 days and the Root Squared Error Method was 32 days. But taking into account the accuracy of calculation it was chosen the term of 29 days.

\section{Conclusions}

In the presented paper it was analyzed the problem of a production process scheduling. This process could be elaborated using different approaches [15 - 17]. It must be stressed that this process is strongly related with the ordered material and adopted welding condition and parameters $[18,19]$.

Due to conducted analysis it was elaborated the realistic production schedule for the analyzed shearer loader. Three resource buffers BZ1 (for tasks L, E), BZ2 (for tasks J, A) and BZ3 (for tasks $\mathrm{M}, \mathrm{N}$ ) were introduced. The buffer sizes and durations of tasks were estimated on the basis of statistical analysis. Historical data from surveys of employees allowed verifying the availability and unavailability of staff for the modified tasks. Statistical analysis concerning forecasting the parameters for describing the distribution of time availability and unavailability of these resources for the next planning period showed that it is possible to reduce the total time of analyzed task by 75 days. At the same time the sum of the resource buffers amounted to 25 days. The introduction of these buffers caused the change in the deadline for project completion. The calculation of the duration of noncritical tasks and the size of the feeding buffer BZA for this sequence of task was based on the parameters estimation of the normal distribution that governs these tasks realization. The modified time of these tasks was shortened by 51 days and the entered buffer size was 11 days. The introduction of this buffer did not result in changes in the date of the project completion. Additionally three feeding buffers for single tasks (BZA1, BZA2 and BZA3) were introduced. The tasks, to which these buffers have been allocated, were analyzed whether they are governed by the normal distribution. Basing on the calculation of parameters for the normal distribution (average value and the standard deviation) it was set the sizes of particular buffers. The introduction of these buffers resulted in a total reduction of tasks duration by 48 days. These changes did not affect the project completion. Finally it 
was introduced the project Buffer BP. It was assessed by two different methods: of half of a chain and method of Root Squared Error. As the result of calculations it was obtained two different project buffer sizes, respectively 29 days and 36 days. Due to the fact that in the Root Squared Error method the results were obtained with a relatively low probability it was decided to select the result obtained with the first method. The introduction of the project buffer and the task with newly determined duration times, in the critical chain, caused the change of the project completion date. The project was shortened by 56 days.

Generally the result of network planning using the CCPM method for the project of mining shearer loader was shortening the term of the project completion. If the project will be performed without the use of buffers, it is estimated that it will be completed in 123 day. However, in the case of utilization of all buffers, it is estimated that the project will end no later than in the 172 day. The analysis of previous projects and presented results showed a significant reduction of the project cost as well as the project duration. It is mainly related with the fact of eliminating the critical situations related with resource conflicts and more realistic predictions of the project realization terms. The proposed method is the most appropriate for projects with more restricted availability of resources. In the case of the analyzed project it gave a reduction of the project cost by $8 \%$. The project duration, in comparison to the longest previous project, was about $14 \%$.

\section{References}

1. L, P. Leach, Critical Chain Project Management (Artech House Publishers, London, 2004)

2. D. Updegrove, The Critical Chain Implementation Handbook (CreateSpace Independent Publishing Platform, North Charleston, 2014)

3. Ch. Schwindt, J. Zimmermann (eds.), Handbook on Project Management and Scheduling (Springer Verlag, Heidelberg, 2015)

4. G. K. Rand, Int. J. of Proj. Man. 18/3. 173 (2000)

5. Zh. Zheng, Z. Guo, Y. Zhu, X. Zhang, J. of Neurocomp. 143, 282 (2014)

6. Z. A. Banaszak, M. B. Zaremba, J. of Intell. Man. 17/6, 641 (2006)

7. A. Hutanu, G. Prostean, A. Badea, Procedia - Soc. and Behav. Sc. 197, 1416 (2015)

8. F, Marle,L.-A. Vidal, Managing Complex, High Risk Projects: A Guide to Basic and Advanced Project Management (Springer Verlag, Heidelberg, 2016)

9. O. I. Tukel, W.O. Rom, S. D. Eksioglu, Eur. J. of Op. Res. 172/2, 401-416 (2006)

10. E. M. Goldratt, Critical Chain (The North River Press, Great Barrington, 2002)

11. http://prototypen.de/objetpolyjet-stl-140.html

12. A. Gwiazda, W. Banaś, A. Sękala, K. Foit, P. Hryniewicz, G. Kost, IOP Conf. Ser.: Mater. Sci. Eng. 95, doi:10.1088/1757-899X/95/1/012104 (2015)

13. A. Gwiazda, App. Mech. and Mat. 474, 147 (2014)

14. http://www.cat.com/en_ZA/products/new/equipment/undergroundlongwall/shearers/18346615.html

15. G. Ćwikła, D. Krenczyk, A. Kampa, G. Gołda, IOP Conf. Ser.: Mater. Sci. Eng. 95, (2015)

16. I. Paprocka, W. Kempa, K. Kalinowski, C. Grabowik, IOP Conf. Ser.: Mater. Sci. Eng. 95, (2015)

17. K. Foit, A. Gwiazda, W. Banaś, A. Sękala, P. Hryniewicz, IOP Conf. Ser. Mater. Sci. Eng. 95, (2015)

18. S. Topolska, J. Łabanowski, Mat in Tech. 49/4, 481 (2015)

19. J. Łabanowski, A. Świerczyńska, S. Topolska, Pol. Mar. Res. 21/4, 108 (2014) 